\title{
Omentin-1 effects on mesenchymal stem cells: proliferation, apoptosis, and angiogenesis in vitro
}

Li Yin ${ }^{1,2}$, Dan Huang ${ }^{1,2}$, Xinxin Liu ${ }^{1,2}$, Yongshun Wang ${ }^{1,2}$, Jingjin Liu ${ }^{1,2}$, Fang Liu ${ }^{1,2}$ and Bo Yu $u^{1,2^{*}}$

\begin{abstract}
Background: Mesenchymal stem cells (MSCS) are emerging as an extremely promising therapeutic agent for tissue repair. However, limitations exist such as the low numbers of MSCs obtained from donors, and the poor survival and function of donor cells. Omentin-1, a new fat depot-specific secretory adipokine, exerts proproliferation, prosurvival, and proangiogenic functions in certain cells via an Akt-dependent mechanism; however, little is known about the influence of omentin-1 on MSCs.
\end{abstract}

Methods: MSCs were isolated from 60-80 g donor rats. Cell proliferation was assessed with CCK-8 and EdU assay. Cell cycle, apoptosis ratio, reactive oxygen species concentration, and mitochondrial membrane potential were detected by flow cytometry. Hoechst 33342 dye was used to assess morphological changes of apoptosis. Expression levels of Akt, FoxO3a, GSK-3ß, and apoptosis- and cell cycle-associated proteins were detected by Western blotting. Tube formation assay was used to test the angiogenesis role of conditioned medium from MSCs in vitro. The cytokine secretion was assessed by ELISA.

Results: After treatment with omentin-1 (100-800 ng/ml), MSCs displayed a higher proliferative capacity with an increasing number of cells in the S and $\mathrm{G} 2$ phase of the cell cycle. Moreover, omentin-1 preconditioning for $1 \mathrm{~h}$ could protect MSCs against $\mathrm{H}_{2} \mathrm{O}_{2}$-induced apoptosis in a concentration-dependent manner. Furthermore, omentin-1 pretreatment reduced the excessive reactive oxygen species. Western blots revealed that increased $\mathrm{BCl}-2$ and decreased Bax appeared in MSCs after omentin-1 incubation, which inhibited the mitochondrial apoptosis pathways with evidence showing inhibition of caspase-3 cleavage and preservation of mitochondrial membrane potential. Omentin-1 could enhance angiogenic growth factor secretion and elevate the ability of MSCs to stimulate tube formation by human umbilical vein endothelial cells (HUVECS). Furthermore, omentin-1 enhanced Akt phosphorylation; however, blockade of the PI3K/Akt pathway with an inhibitor, LY294002 (20 MM), suppressed the above beneficial effects of omentin-1.

Conclusion: Omentin-1 can exert beneficial effects on MSCs by promoting proliferation, inhibiting apoptosis, increasing secretion of angiogenic cytokines, and enhancing the ability for stimulating tube formation by HUVECs via the PI3K/Akt signaling pathway. Thus, omentin-1 may be considered a candidate for optimizing MSC-based cell therapy.

Keywords: Omentin-1, Mesenchymal stem cells, Proliferation, Apoptosis, Reactive oxygen species, Mitochondrial apoptosis pathways, Angiogenesis

\footnotetext{
*Correspondence: dryu_hmu@163.com

'Key Laboratories of Education Ministry for Myocardial Ischemia Mechanism,

The Second Affiliated Hospital of Harbin Medical University, 148 Baojian

Road, Harbin 150086, People's Republic of China

${ }^{2}$ Department of Cardiology, The Second Affiliated Hospital of Harbin Medical

University, 148 Baojian Road, Harbin 150086, People's Republic of China
}

\section{Biomed Central}

(c) The Author(s). 2017 Open Access This article is distributed under the terms of the Creative Commons Attribution 4.0 International License (http://creativecommons.org/licenses/by/4.0/), which permits unrestricted use, distribution, and reproduction in any medium, provided you give appropriate credit to the original author(s) and the source, provide a link to the Creative Commons license, and indicate if changes were made. The Creative Commons Public Domain Dedication waiver (http://creativecommons.org/publicdomain/zero/1.0/) applies to the data made available in this article, unless otherwise stated. 


\section{Background}

Mesenchymal stem cells (MSCs) are adult stem cells and have attracted great interest for cell-based therapeutic strategies for tissue injury, such as myocardial infarction [1], stroke [2], and hind limb ischemia [3], because of their easy preparation, immunologic privilege, and ethical advantage. Unfortunately, the insufficient numbers of such MSCs obtained from donors [4], the low survival in the harsh environment, and the poor function of donor cells $[5,6]$ has limited their therapeutic potential. Remarkably, PI3K/Akt-related signaling pathways are known to function as core mechanisms by regulating multiple cellular behaviors of MSCs such as proliferation [7, 8], survival [9, 10], proangiogenesis [11], cytokine production [12], and so on. Therefore, optimized strategies to activate the PI3K/Akt pathway in MSCs need to be developed for better outcomes in stem cell therapy.

Omentin-1, referred to as intelectin-1, is a new fat depot-specific secretory adipokine that is a hydrophilic protein with a molecular weight of $34 \mathrm{kDa}$ composed of 313 amino acids [13]; it has well-established effects on the regulation of insulin sensitivity [14], modulation of energy metabolism [15], and distribution of body fat [14, 16]. Omentin-1 is mainly expressed in visceral adipose tissue rather than in subcutaneous adipose tissue. Moreover, plasma omentin-1 levels in a healthy individual are reported to be roughly $370 \pm 20 \mathrm{ng} / \mathrm{mL}$ [17], but are significantly reduced in obese patients, those with impaired glucose tolerance, and, particularly, in patients with type 2 diabetes mellitus [17-19] and cardiovascular disorders such as atherosclerosis [20] and ischemic heart disease [21]. Current data suggest that omentin-1 has protective effects on the cardiovascular system [22, 23]. Maruyama and colleagues [22] confirmed that, in a hind limb ischemia mouse model, omentin-1 enhanced blood flow recovery and capillary density in ischemia limbs of wild-type mice, and at the cellular level omentin-1 increased endothelial cell differentiation into vascularlike structures and lowed their apoptotic activity via PI3K/Akt-dependent signaling. Recently, Kataoka et al. [23] demonstrated that omentin-1 ameliorates acute ischemia injury in the heart by suppressing cardiomyocyte apoptosis through AMP-activated protein kinase (AMPK) and the Akt signaling pathway. However, to our knowledge, there has been no visual evidence of the protective effects of omentin-1 on the biological functions of MSCs. Therefore, we designed the present study to explore the potential role of omentin-1 on the proliferation, survival, angiogenesis, and cytokine production of MSCs and to elucidate whether the modulatory role of omentin-1 in MSCs was due to the activation of the PI3K/Akt signaling pathway.

\section{Methods}

\section{Cell isolation and cultivation}

MSCs were isolated from the bone marrow of SpragueDawley (SD) rats (weighing 60-80 g), as previously described [24, 25]. All of the SD rats were obtained from the Laboratory Animal Science Department, the Second Affiliated Hospital of Harbin Medical University (Harbin, China). All of the study procedures were approved by the Institutional Animal Care and Use Committee of Harbin Medical University (reference no. KY2016-180). This study was conducted in compliance with the Guide for the Care and Use of Laboratory Animals published by the National Academy Press (National Institutes of Health, revised in 1996). Briefly, the femurs and tibias were removed from the $\mathrm{SD}$ rats and the bone marrow was washed out using $10 \mathrm{ml}$ of Dulbecco's modified Eagle's medium/Nutrient Mixture F-12 (DMEM/F12; Gibco, Grand Island, NY, USA) with 1\% penicillin/streptomycin (Beyotime Institute of Biotechnology, Nantong, China). The cells were centrifuged at $300 \times \mathrm{g}$ for $5 \mathrm{~min}$. The resulting cell pellets were resuspended in $6 \mathrm{ml}$ of DMEM/F12 supplemented with $10 \%$ fetal bovine serum (Gibco) and $1 \%$ penicillin/streptomycin and plated in a $25 \mathrm{~cm}^{2}$ plastic flask at $37{ }^{\circ} \mathrm{C}$ in a humidified atmosphere containing $5 \%$ $\mathrm{CO}_{2}$ to allow the adherence of the MSCs. After culturing for 3 days, the medium was changed, and the nonadherent cells were removed. The medium was replaced every 2 days. Upon reaching 80-90\% confluence, the adherent cells were released from the dishes using $0.25 \%$ trypsin (Beyotime Institute of Biotechnology) and expanded at a dilution of 1:2 or 1:3. All subsequent experiments were performed using MSCs from passages 3-5.

Human umbilical vein endothelial cells (HUVECs) (American Type Culture Collection (ATCC), Manassas, VA, USA) were cultured in a $25 \mathrm{~cm}^{2}$ plastic flask in endothelial basal medium (EBM-2; Lonza) with $5 \%$ fetal bovine serum and $1 \%$ penicillin/streptomycin. The medium was replaced every 2 days. Upon reaching 80-90\% confluence, the cells were released from the dishes using $0.25 \%$ trypsin (Beyotime Institute of Biotechnology), expanded at a dilution of $1: 2$ or $1: 3$ and used for experiments from passages $3-4$.

\section{Cell proliferation assay}

Cell proliferation was assessed with the cell counting kit-8 (CCK-8) assay (Beyotime Institute of Biotechnology) and 5-ethynyl-2'-deoxyuridine (EdU) proliferation assay (RiboBio Co., China). For the CCK-8 test, cells were plated onto 96 -well plates $\left(3 \times 10^{3}\right.$ cells/well $)$ with omentin-1 (0-800 ng/ml; Omentin Human Recombinant; Prospect, Ness-Ziona, Israel) in a triplicate pattern. Assays were performed from 1 to 7 days after plating with the addition of $100 \mu \mathrm{l}$ of fresh medium in $10 \mu \mathrm{l}$ of CCK- 8 solution for another $2 \mathrm{~h}$ at $37^{\circ} \mathrm{C}$. The optical density (OD) 
at $450 \mathrm{~nm}$ was measured. The assay was repeated three times.

For the EdU assay, cells were incubated with omentin$1(800 \mathrm{ng} / \mathrm{ml})$ for 5 days in 96-well plates, and then assessed using an EdU assay kit (RiboBio Co., China) according to the manufacturer's instructions. The EdUpositive cells were viewed under fluorescence microscopy (DMI4000B; Leica, Wetzlar, Germany) and the number calculated by counting at least three random separate fields.

\section{Cell cycle assay}

The MSCs were cultured in serum-free medium overnight to synchronize the cell cycle before treatment. After treatment with omentin-1 $(0-800 \mathrm{ng} / \mathrm{ml})$ for 5 days, MSCs were dissociated into single cells with trypsin and fixed with prechilled $70 \%$ ethanol. These cells were stained with the Cycletest ${ }^{\text {tw }}$ Plus kit (BD Biosciences, San Jose, CA, USA) according to the manufacturer's instruction. Cell cycle analyses were carried out with flow cytometry (FACSCanto II), and data were analyzed using BD FACSDiva software (Becton-Dickinson, San Jose, CA, USA).

\section{Cell apoptosis assay}

We used hydrogen peroxide and serum deprivation to induce MSC apoptosis. In brief, after cells were washed with phosphate-buffered saline (PBS), the culture medium was replaced with serum-free DMEM/F12 supplemented with $400 \mu \mathrm{M} \mathrm{H}_{2} \mathrm{O}_{2}$ and then the cells were placed at $37{ }^{\circ} \mathrm{C}$ for $6 \mathrm{~h}$. For omentin-1 protection experiments, omentin- $1(0-800 \mathrm{ng} / \mathrm{ml})$ was added to the MSC medium for $1 \mathrm{~h}$ before $\mathrm{H}_{2} \mathrm{O}_{2}$ treatment and then continuously incubated with $400 \mu \mathrm{M} \mathrm{H}_{2} \mathrm{O}_{2}$ for $6 \mathrm{~h}$.

Cell death was assessed using the Annexin V-FITC/ propidium iodide (PI) Apoptosis Detection kit (BD Biosciences) and Hoechst 33342 stain (Beyotime Institute of Biotechnology). According to the manufacturer's instructions for the Annexin V-FITC/PI Apoptosis Detection Kit, cells were harvested, washed in ice-cold PBS, and resuspended in $300 \mu \mathrm{l}$ of binding buffer. Five microliters of Annexin V-FITC solution was added to the cells and incubated for $30 \mathrm{~min}$ at $4{ }^{\circ} \mathrm{C}$ in the dark. This was followed by further incubation with $5 \mu \mathrm{L}$ PI for $5 \mathrm{~min}$, and then they were analyzed immediately by bivariate flow cytometry using a BD FACSCanto cytometer equipped with FACSDiva Pro software (Becton-Dickinson, San Jose, CA, USA). Approximately $1-5 \times 10^{5}$ cells were analyzed in each sample.

The chromatin dye Hoechst 33342 was used to assess the morphological changes of apoptosis. MSCs were fixed for $30 \mathrm{~min}$ in PBS containing 1\% glutaraldehyde at room temperature, then washed twice with PBS and exposed to $5 \mathrm{mg} / \mathrm{ml}$ of Hoechst 33342 for $30 \mathrm{~min}$ at room temperature. The cells were then observed with a fluorescence microscope. Apoptotic cells were characterized by morphological alterations, such as condensed nuclei and cell shrinkage.

\section{Flow cytometry analysis of mitochondrial membrane potential (MMP or $\Delta \Psi \mathrm{m}$ ) and reactive oxygen species (ROS) levels}

The loss of $\Delta \Psi \mathrm{m}$ was determined using the JC-1 Mitochondrial Membrane Potential assay kit (Beyotime Institute of Biotechnology). Briefly, cells were washed with ice-cold PBS and then stained with $2.5 \mathrm{~g} / \mathrm{ml} \mathrm{JC-}$ 1 for $30 \mathrm{~min}$ at $37{ }^{\circ} \mathrm{C}$. After being washed with binding buffer, the cells were analyzed by flow cytometry (FACSCanto II). Results are presented as relative monomer-to-aggregate (green/red) fluorescence intensity ratio.

Cellular ROS levels were determined using a reactive oxygen species (ROS) assay kit (Beyotime Institute of Biotechnology). Briefly, the cells were incubated with the diluted fluoroprobe 2',7'-dichlorodihydrofluorescein diacetate (DCFH-DA; Beyotime Institute of Biotechnology) for $20 \mathrm{~min}$ at $37^{\circ} \mathrm{C}$ with slight shaking every $5 \mathrm{~min}$. After washing with serum-free culture medium, the cells were collected and examined by flow cytometry (FACSCanto II) at excitation and emission wavelengths of 488 and $525 \mathrm{~nm}$, respectively.

\section{Western blot analysis}

At the end of the treatment period, the MSCs were harvested and lysed with ice-cold RIPA lysis buffer, and the homogenate was centrifuged at $12,000 \times \mathrm{g}$ for $10 \mathrm{~min}$ at $4{ }^{\circ} \mathrm{C}$. Total protein in the supernatant was quantified using a BCA Protein assay kit, and an aliquot (30$50 \mu \mathrm{g})$ from each sample was separated by $12 \%$ sodium dodecyl sulfate-polyacrylamide gel electrophoresis (SDSPAGE). The protein band was transferred onto polyvinylidene difluoride (PVDF) membranes blocked with $8 \%$ fat-free milk in Tris-buffered saline (TBS) with $0.5 \%$ Tween-20 for $60 \mathrm{~min}$ at $37{ }^{\circ} \mathrm{C}$, followed by treatment with the following primary antibodies at $4{ }^{\circ} \mathrm{C}$ overnight: rabbit monoclonal against Akt (cst-4691 s), phosphorylated Akt (p-Akt (Ser473); cst-4060 s, p-Akt (Thr308); cst-4056 s), Bax (cst-2772 s), Bcl-2 (cst-2876 s), and caspase-3 (cst-9662 s) (all from Cell Signaling Technology, Danvers, MA, USA), phosphorylated FoxO3a (phosphoFoxO3a (Thr32); AF605), FoxO3a (AF609), phosphorylated GSK-3 $\beta$ (phospho-GSK-3 $\beta$ (Ser9); AG753), GSK-3 $\beta$ (AG751), p21 (AP021), and p27 (AP027) (all from Beyotime Institute of Biotechnology), cyclin D1 (sc-70899) and cyclin E (sc-377100) (both from Santa Cruz Biotechnology, CA, USA), and mouse polyclonal antibody against $\beta$-actin (TA-09; Zhongshan Golden Bridge Biotechnology, Beijing, China). After washing in TBS with Tween-20 
(TBS-T) buffer, the membranes were further incubated with horseradish peroxidase-conjugated anti-mouse (ZB2305; Zhongshan Goldenbridge Biotechnology) and antirabbit (sc-2357) secondary antibodies (Santa Cruz Biotechnology) for $60 \mathrm{~min}$ at $37{ }^{\circ} \mathrm{C}$. Subsequently, the membranes were washed in TBS-T solution three times, followed by the addition of TBS solution, and visualized using the ECL chemiluminescence detection system with BeyoECL Plus (Beyotime Institute of Biotechnology). Densitometric analysis of the protein bands was carried out using Quantity One software (Bio-Rad, Hercules, CA, USA).

\section{In vitro tube formation assay}

The effect of MSC-conditioned medium on capillary-like tube formation on Matrigel (BD Bioscience) in vitro was evaluated. Conditioned media were collected from MSCs pretreated with omentin-1 or MSCs alone. To avoid the direct influence of omentin-1 on the capillary-like tube formation, after treatment with omentin-1 $(800 \mathrm{ng} / \mathrm{ml})$ for $24 \mathrm{~h}$, MSCs were washed with PBS twice and then incubated with serum-free medium for the next $48 \mathrm{~h}$.

HUVECs were seeded in 48-well plates coated with growth factor reduced Matrigel (BD Bioscience; $100 \mu \mathrm{l}$ per well) at a concentration of $2 \times 10^{4}$ cells per well and MSC-conditioned medium ( $300 \mu \mathrm{l}$ per well) was added. Three wells were used for each sample of conditioned medium. Supplement-free and serum-free endothelial basal medium (EBM-2; Lonza) was utilized as a negative control. Plates were placed into a $\mathrm{CO}_{2}$-incubator at $37{ }^{\circ} \mathrm{C}$ and capillary-like structures were assayed at $6 \mathrm{~h}$ under a light microscope (Leica). The total length of the tubular structures was counted in five random fields of view per well using Photoshop CS5 software (Adobe, San Jose, CA, USA).

\section{Enzyme-linked immunosorbent assay (ELISA)}

To ascertain whether omentin-1 pretreatment results in an increase in angiogenic humoral factor release from MSCs (vascular endothelial growth factor (VEGF), fibroblast growth factor-2 (FGF-2), hepatocyte growth factor (HGF), and insulin-like growth factor-1 (IGF-1)), MSCs were treated with omentin-1 $(800 \mathrm{ng} / \mathrm{ml})$ for $24 \mathrm{~h}$ and washed with PBS twice and then incubated with serumfree medium for the next $48 \mathrm{~h}$. After that, the medium was collected. The levels of VEGF, FGF-2, HGF, IGF-1, interleukin-1 receptor antagonist (IL-1ra), tumor necrosis factor-stimulated gene-6 (TSG-6), interleukin (IL)-6, and IL-8 released from MSCs into the culture medium were directly measured by their respective ELISA kit according to the manufacturer's instructions (R\&D Systems Inc., Minneapolis, MN, USA; Sigma-Aldrich, MO, USA). Basal medium was used as a control. The absorbance was measured at 450 and $570 \mathrm{~nm}$. To avoid the influence of cell numbers on cytokines levels, the data were normalized to cell counts. The assays were repeated three times.

\section{Reagent treatment}

To investigate the role of the PI3K/Akt pathway in omentin-1-mediated MSC proliferation, and survival, proangiogenesis, and cytokine production, LY294002 $(20 \mu \mathrm{m} / \mathrm{L}$; Cell Signaling Technology) was added to the MSC medium for $1 \mathrm{~h}$ before omentin-1 treatment to block the PI3K/Akt pathway activation. All subsequent experiments were performed as described above.

\section{Statistical analysis}

Data are expressed as mean \pm standard deviation. Comparisons between two groups were measured using unpaired Student's two-tailed $t$ test, and differences among groups were detected by one-way analysis of variance with Bonferroni post hoc test using the statistical software SPSS package v19.0 (SPSS, Inc., Chicago, IL, USA). $P<0.05$ was considered significantly significant.

\section{Results}

Omentin-1 activated PI3K/Akt signaling pathway in MSCs

Previous studies have shown that omentin-1 could activate the PI3K/Akt signaling pathway in various cells, such as macrophages [26], osteoblasts [27], vascular smooth muscle cells [28], endothelial cells [29], and cardiomyocytes [23]; this pathway plays an important role in MSCs. To further elucidate whether omentin-1 could activate the PI3K/Akt signaling pathway in MSCs, phosphorylation of Akt (Ser473 and Thr308) was detected by Western blot under increasing concentrations (0$800 \mathrm{ng} / \mathrm{ml})$ or time-periods of stimulation $(0-120 \mathrm{~min})$ of omentin-1. As shown in Fig. 1a and b, omentin-1 treatment increased the levels of phosphorylated Akt (p-Akt) in a concentration-dependent manner. In the presence of the PI3K/Akt inhibitor, LY294002, p-Akt expression was strongly inhibited (Fig. 1a and b), indicating that omentin1 was the upstream activator of the PI3K/Akt pathway in MSCs. Meanwhile, we observed that the expression of phosphorylated Akt proteins was enhanced by omentin-1 in a time-dependent manner, peaking at $60 \mathrm{~min}$ (Fig. 1c and d). FoxO3a and GSK-3 $\beta$ are downstream effectors of PI3K-Akt signaling [30, 31], and are well known to be implicated in regulation of MSC proliferation and survival [25, 32-34]. As shown in Fig. 1e and f, omentin-1 $(800 \mathrm{ng} / \mathrm{ml})$ exposure also caused a significant increase in the phosphorylation of FoxO3a and GSK-3 $\beta$ in MSCs. Furthermore, LY294002 abolished the phosphorylation of FoxO3a and GSK-3 $\beta$ subsequent to omentin-1 treatment (Fig. 1e and f). 


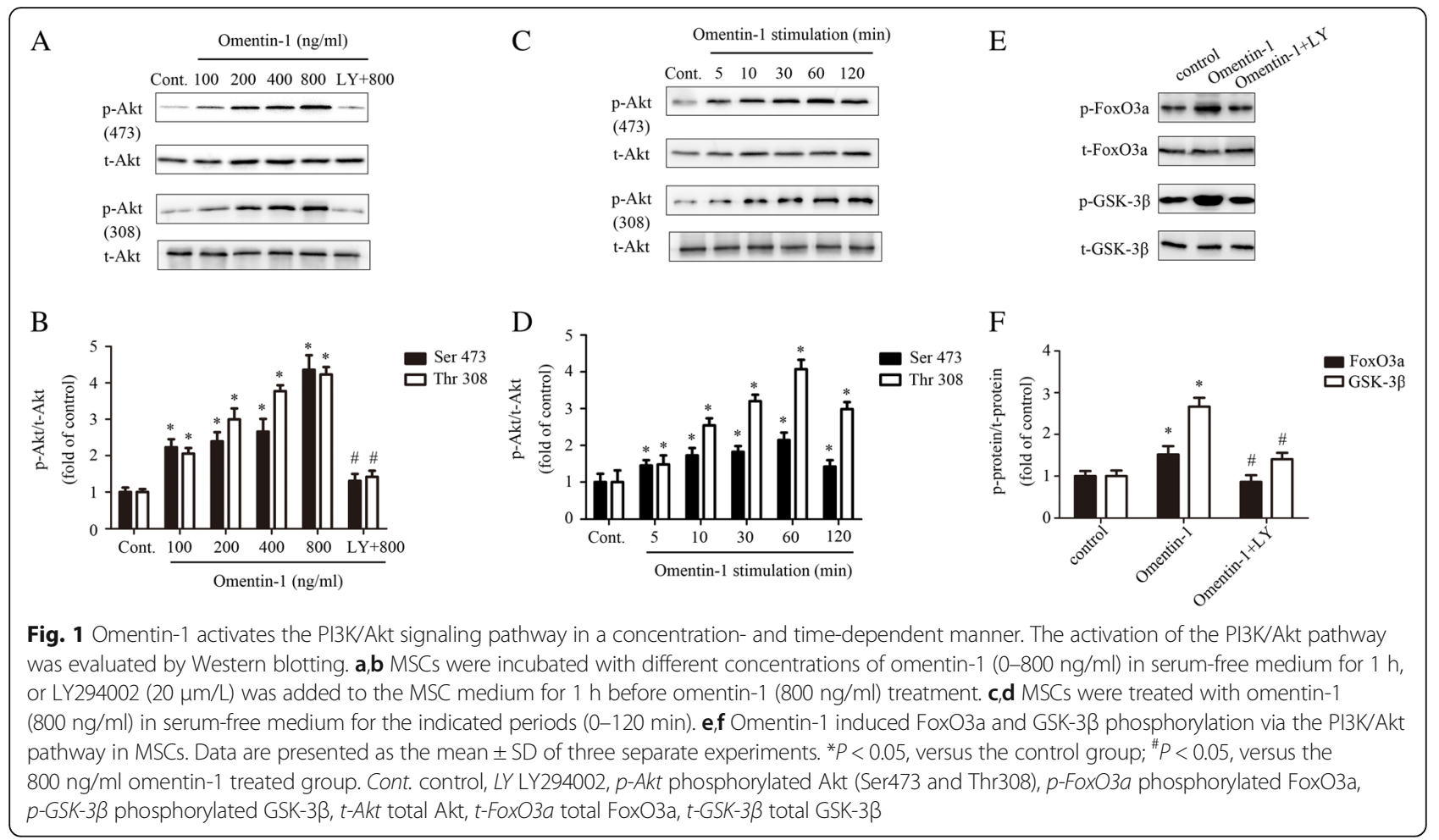

\section{Omentin-1 promoted MSC proliferation via PI3K/Akt}

Experiments were carried out to investigate the effect of omentin-1 on MSC proliferation. The cell cycle, proliferation ability, and cell growth curve were tested by flow cytometry, EdU assay, and CCK-8, respectively. Varying doses of omentin-1 were added to the culture medium for 5 days following $24 \mathrm{~h}$ of serum starvation, and then flow cytometry showed the omentin-1 groups had a higher percentage of $\mathrm{S}$ and G2 phase cells compared with the control group in a concentration-dependent manner (Fig. 2a and b), while EdU-positive cells were significantly increased in the omentin-1 group $(800 \mathrm{ng} / \mathrm{ml})$ than in the control group (omentin-1 group, $22 \pm 5$ versus control group, $5 \pm 3 ; P<0.05$; Fig. $2 \mathrm{c}$ and $\mathrm{d}$ ). In line with flow cytometry and EdU assay data, the growth curves assessed by CCK-8 shown in Fig. 2e revealed that the growth ability of the MSCs improved gradually with increases in the omentin-1 concentration. However, there were no significant differences between the $100 \mathrm{ng} / \mathrm{ml}$ group and the control group ( $100 \mathrm{ng} / \mathrm{ml}$ group, $0.25 \pm 0.02$ versus control group, $0.23 \pm 0.03$; no significance; Fig. $5 \mathrm{e}$ ). To further confirm whether the PI3K/Akt signaling pathway is essential to the proliferation effect of omentin-1 on MSCs, cells were preincubated with LY294002 $(20 \mu \mathrm{m} / \mathrm{L})$ for $1 \mathrm{~h}$ prior to omentin-1 treatment; we found that the PI3K/Akt inhibitor LY294002 dramatically suppressed this effect of omentin-1 on MSC proliferation (Fig. 2). These findings confirm that omentin-1 could promote MSC proliferation through the PI3K/Akt pathway in a concentration-dependent manner.

Cyclin D1 and cyclin E form the CDK4/6-cyclin D1 and CDK2-cyclin E complexes, which together promote the $\mathrm{G} 1 / \mathrm{S}$ phase progression [35]. p21/p27 can bind to CDK2/4/6, playing a role in blocking the effect of cyclinCDK complexes, and thus preventing G1/S phase transition [35]. Western blot results showed that the expression of cyclin D1 and cyclin E were significantly increased, while the expression of cyclin-dependent kinase inhibitors (CKIs) p21 and p27 were reduced markedly (Fig. 2f-h). However, pretreatment with LY294002 reversed this trend (Fig. $2 \mathrm{f}-\mathrm{h}$ ), suggesting that omentin1 increased the proliferative capacity of MSCs through the PI3K/Akt pathway which promoted the cell cycle via a cyclin D1/E-p21/p27-dependent pathway.

\section{Omentin-1 inhibited $\mathrm{H}_{2} \mathrm{O}_{2}$-induced MSC apoptosis through PI3K/Akt}

Considering that apoptosis and necrosis caused by oxidative stress injury reduces the tissue repair capacity of MSCs [36], we examined the protective effects of omentin- 1 on MSC death induced by $\mathrm{H}_{2} \mathrm{O}_{2}$. MSCs were pretreated with omentin-1 (0-800 ng/ml) for $1 \mathrm{~h}$ before being exposed to $400 \mu \mathrm{M} \mathrm{H}_{2} \mathrm{O}_{2}$ for $6 \mathrm{~h}$, and the number of dead cells was evaluated by flow cytometry. $\mathrm{H}_{2} \mathrm{O}_{2}$ markedly increased the Annexin $\mathrm{V}^{+} / \mathrm{PI}^{-}$cells (cells exposed to $\mathrm{H}_{2} \mathrm{O}_{2}, 39.20 \pm 4.7 \%$ versus normal cells, $8.76 \pm$ 1.2\%; $P<0.05$; Fig. $3 \mathrm{a}$ and $\mathrm{c}$ ), but not the Annexin $\mathrm{V}^{+} / \mathrm{PI}^{+}$ 


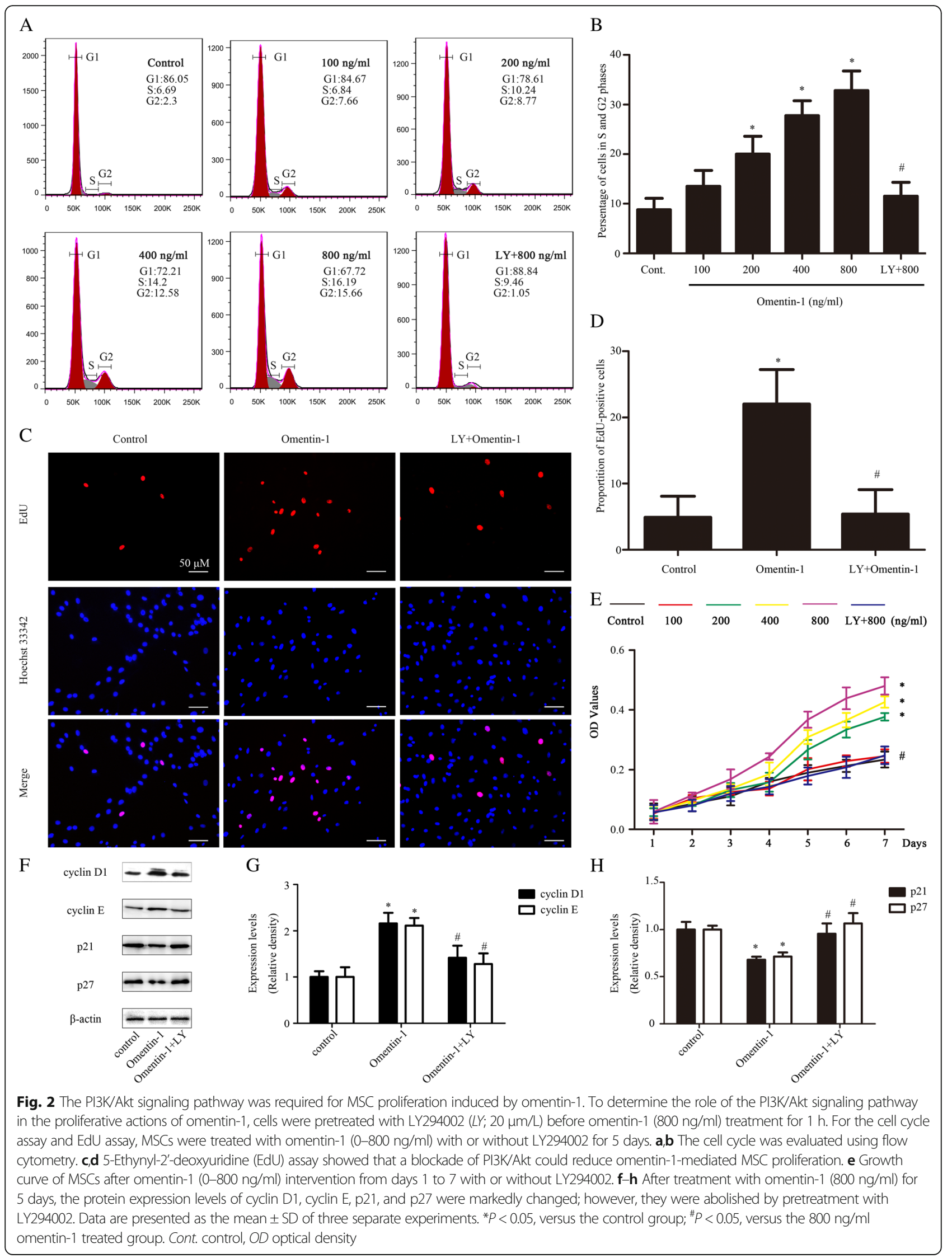




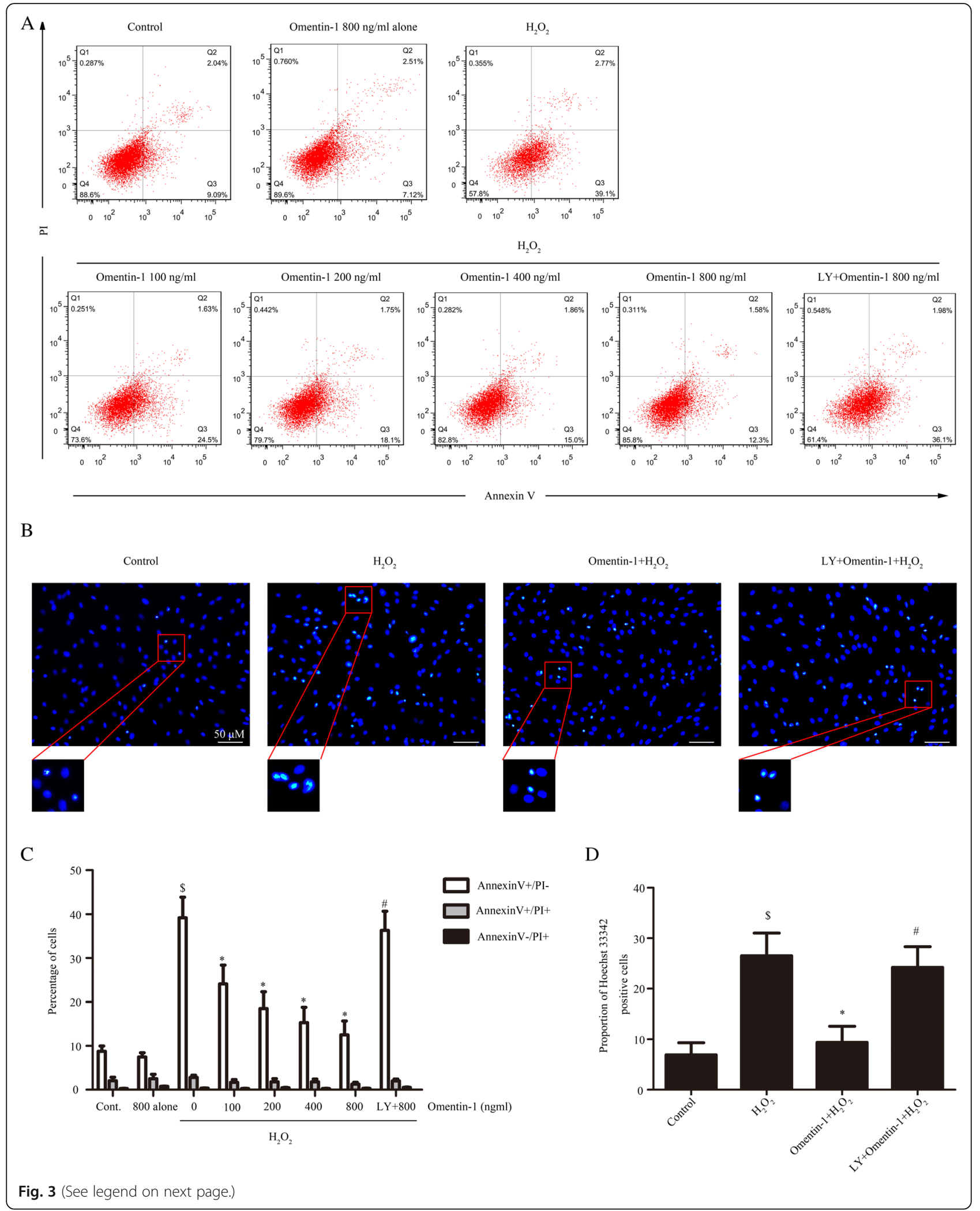


(See figure on previous page.)

Fig. 3 PIJK Akt was involved in the antiapoptotic effects of omentin-1 on MSCs under oxidative stress. MSCs were pretreated with omentin-1 $(0-800 \mathrm{ng} / \mathrm{ml})$ for $1 \mathrm{~h}$ and continuously incubated with $400 \mu \mathrm{M} \mathrm{H} \mathrm{O}_{2}$ for $6 \mathrm{~h}$. In order to identify the role of the PI3K/Akt signaling pathway on the antiapoptotic actions of omentin-1, LY294002 (LY; $20 \mu \mathrm{m} / \mathrm{L}$ ) was added to the MSC medium for $1 \mathrm{~h}$ prior to omentin-1 (800 ng/ml) treatment. a,c Cell apoptosis was confirmed by Annexin V/propidium iodide $(P I)$ and $\mathbf{b}$,d Hoechst 33342 staining. Data are presented as the mean \pm SD of three separate experiments. ${ }^{\$} P<0.05$, versus the control group; ${ }^{*} P<0.05$, versus the $\mathrm{H}_{2} \mathrm{O}_{2}$ group; ${ }^{\#} P<0.05$, versus the $800 \mathrm{ng} / \mathrm{ml}$ omentin-1 treated group. Cont. control

cells compared with the control group (cells exposed to $\mathrm{H}_{2} \mathrm{O}_{2}, 2.27 \pm 0.5 \%$ versus normal cells, $2.04 \pm 0.8 \%$; no significance; Fig. 3a and c), suggesting that $\mathrm{H}_{2} \mathrm{O}_{2}$ mainly induced the early apoptosis and had no effect on the late apoptosis or necrosis under our experimental conditions. When the MSCs were pretreated with omentin- 1 for $1 \mathrm{~h}$ before $\mathrm{H}_{2} \mathrm{O}_{2}$, the percentage of Annextin $\mathrm{V}^{+} / \mathrm{PI}^{-}$cells significantly decreased in a concentration-dependent manner. There was also no significant difference in cell apoptosis between the control cells and those pretreated with $800 \mathrm{ng} / \mathrm{ml}$ omentin-1 alone (Fig. 3a and c). To further confirm the antiapoptotic effects of omentin-1, morphological changes were observed using Hoechst 33342 staining. As seen in Fig. $3 \mathrm{~b}$ and d, the data show that $\mathrm{H}_{2} \mathrm{O}_{2}$ increased cell apoptosis by approximately $20 \%$ (normal cells, $6.9 \pm 2.4 \%$ versus cells exposed to $\mathrm{H}_{2} \mathrm{O}_{2}, 26.5 \pm$ $4.5 \% ; P<0.05)$ and the proportion of Hoechst 33342positive cells was markedly decreased in the presence of omentin-1 (800 ng/ml group, $9.4 \pm 3.2 \%$ versus cells exposed to $\left.\mathrm{H}_{2} \mathrm{O}_{2}, 26.5 \pm 4.5 \% ; P<0.05\right)$. However, the protective effects of omentin-1 were attenuated when cells were preconditioned with LY294002 in both the flow cytometry test $(\mathrm{LY} 294002+800 \mathrm{ng} / \mathrm{ml}$ group, $36.3 \pm$ $4.4 \%$ versus $800 \mathrm{ng} / \mathrm{ml}$ group, $12.5 \pm 3.2 \% ; P<0.05$; Fig. 3a and c) and the Hoechst 33342 staining assay (LY294002 + $800 \mathrm{ng} / \mathrm{ml}$ group, $24.2 \pm 4.1 \%$ versus $800 \mathrm{ng} / \mathrm{ml}$ group, $9.4 \pm 3.2 \% ; P<0.05$; Fig. $3 \mathrm{~b}$ and $\mathrm{d}$ ). These above results indicated that the PI3K/Akt signaling pathway played an important role in the protective effects of omentin-1 on $\mathrm{H}_{2} \mathrm{O}_{2}$-induced MSC apoptosis.

\section{Omentin-1 reduced ROS and protected the function of mitochondria in MSCs via PI3K/Akt}

Excessive exogenous ROS caused by $\mathrm{H}_{2} \mathrm{O}_{2}$ initiates cellular apoptosis that mainly depends on the mitochondrial death pathway whose progress involves the loss of mitochondrial membrane potential $(\Delta \Psi \mathrm{m})$, an imbalance in the $\mathrm{Bax} / \mathrm{Bcl}-2$ ratio, and activation of procaspase-3 [37]. Experiments were carried out to identify whether the antiapoptotic effect of omentin-1 on MSCs under $\mathrm{H}_{2} \mathrm{O}_{2}$ was dependent on reducing ROS and blocking the mitochondrial death pathway. First, the intracellular ROS level of MSCs was analyzed by DCFH oxidation assay. As shown in Fig. 4a, omentin-1 reduced the ROS level in MSCs after $\mathrm{H}_{2} \mathrm{O}_{2}$ treatment in a concentration- dependent manner, and was neutralized by LY294002. Furthermore, the mitochondrial transmembrane potential was measured by JC-1, a mitochondrial $\Delta \Psi \mathrm{m}$ sensitive dye. The results revealed that $\mathrm{H}_{2} \mathrm{O}_{2}$ gave rise to remarkable changes in mitochondrial $\Delta \Psi \mathrm{m}$ compared with the control group $\left(\mathrm{H}_{2} \mathrm{O}_{2}\right.$ group, $4.13 \pm 0.53$ versus control group, $0.63 \pm 0.23 ; P<0.05$; Fig. $4 \mathrm{~b})$. However, pretreatment of MSCs with omentin-1 maintained an electrochemical gradient across the mitochondrial membranes in a concentration-dependent manner, which was also counteracted in the presence of LY294002 (Fig. 4b). Meanwhile, omentin-1 (800 ng/ml) alone had no significant effect on ROS levels and mitochondrial transmembrane potential (Fig. 4a and b). Western blot analysis was then used to measure the expression levels of cleaved caspase-3, procaspase-3, Bax, and Bcl-2, which are well known key mediators of apoptosis. Omentin-1 significantly suppressed the levels of cleaved caspase- 3 and the ratio of $\mathrm{Bax} / \mathrm{Bcl}-2$ under $\mathrm{H}_{2} \mathrm{O}_{2}$ treatment (Fig. 4c). Consistently, the effects of omentin-1 on the proteins mentioned above were abolished by LY294002 (Fig. 4c).

Taken together, the data above suggest that pretreatment with omentin-1 could protect MSCs from exogenous oxidative stress and maintain the function of mitochondria in MSCs via PI3K/Akt.

\section{Omentin-1 elevated the ability of MSCs to stimulate tube formation by HUVECs and enhanced angiogenic growth factor secretion via PI3K/Akt}

The tube formation assay was used to test whether conditioned medium from MSCs treated with omentin-1 could stimulate angiogenesis in vitro. MSCs were treated with omentin-1 $(800 \mathrm{ng} / \mathrm{ml})$ for $24 \mathrm{~h}$ with or without LY294002 and washed with PBS twice and then incubated with serum-free medium for the next $48 \mathrm{~h}$. After that, the medium was collected. The results (Fig. 5a and $\mathrm{b}$ ) indicate that conditioned media from untreated and omentin-1 $(800 \mathrm{ng} / \mathrm{ml})$ preincubated MSCs were able to augment endothelial cell capillary tube-forming capacity in vitro compared with basal medium and, in particular, the maximum proangiogenic effect was observed in the presence of conditioned medium from MSCs with preincubation with omentin-1, suggesting that the paracrine mechanism was involved in the proangiogenic effect of omentin-1 on MSCs. To further 


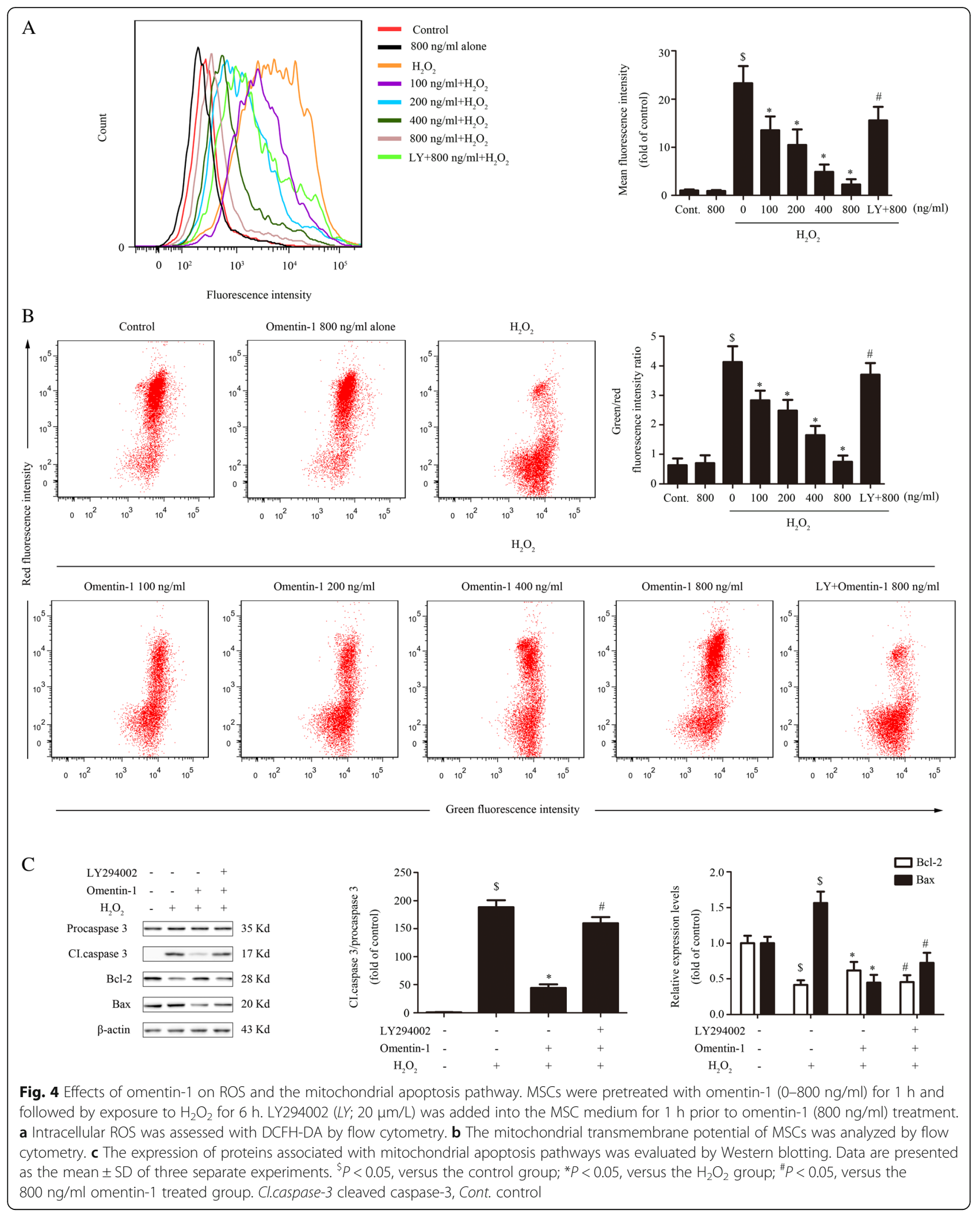




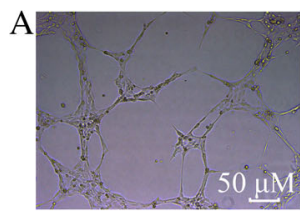

basal medium
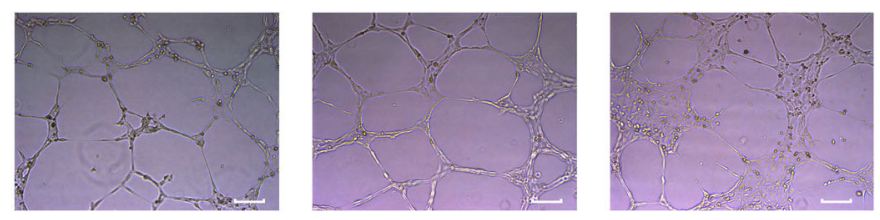

conditioned medium from
MSCs pre-incubated

with LY294002 and

omentin-1
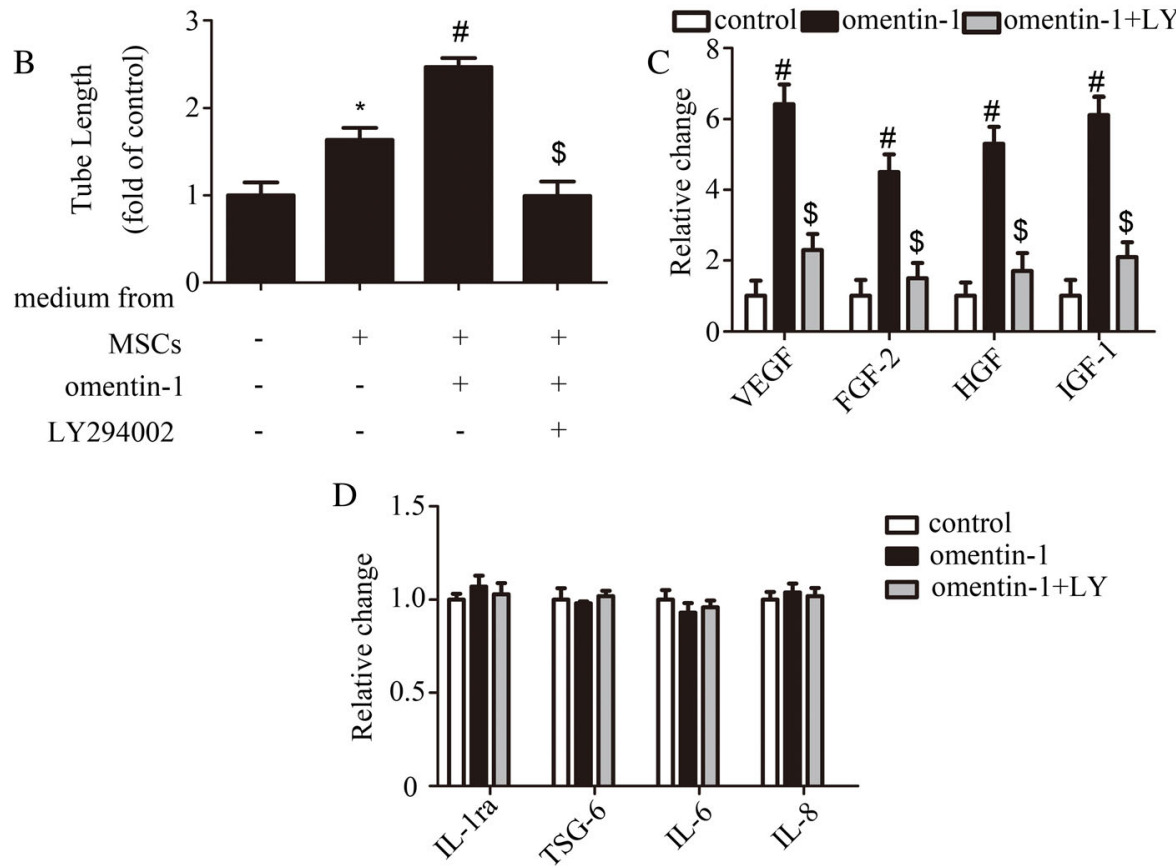

Fig. 5 Effects of omentin-1 on the capillary-like tube formation capacity of the conditioned medium and angiogenic factor secretion. The media were conditioned by only mesenchymal stem cells (MSCs), omentin-1 (800 ng/ml) preincubated MSCs, or LY294002 (LY) and omentin-1 (800 ng/ $\mathrm{ml}$ ) preincubated MSCs. Then the conditioned media were collected. Basal medium was used as a negative control. a,b HUVECs were incubated in each conditioned medium for $6 \mathrm{~h}$ in Matrigel, and the total length of the tube network per field was quantified. c Concentrations of vascular endothelial growth factor (VEGF), fibroblast growth factor-2 (FGF-2), hepatocyte growth factor (HGF), and insulin-like growth factor-1 (IGF-1) in the conditioned medium were measured by ELISA and normalized to cell counts. d Concentrations of interleukin-1 receptor antagonist (IL-1 ra), tumor necrosis factor-stimulated gene-6 (TSG-6), interleukin (IL)-6, and IL-8 in the conditioned medium were measured by ELISA and normalized to cell counts. Data are presented as the mean \pm SD of three separate experiments. ${ }^{*} P<0.05$, versus the basal medium; ${ }^{*} P<0.05$, versus the conditioned medium from the untreated MSC group; ${ }^{\$} P<0.05$, versus the conditioned medium from the omentin-1-treated group

reveal this mechanism, the levels of VEGF, FGF-2, HGF, and IGF-1, as the key proangiogenic factors, were measured by ELISA. A statistically significant increase in all four factors mentioned above was detected in omentin-1 preincubated medium compared with the untreated medium (Fig. 5c). We then explored the role of the PI3K/Akt pathway in this mechanism. Pretreatment of MSCs with LY294002 attenuated the proangiogenic effect of omentin-1 as well as decreased the levels of VEGF, FGF-2, HGF, and IGF-1 in the conditioned medium (Fig. 5a-c). Meanwhile, various anti-inflammatory (IL-1ra and TSG-6) and proinflammatory (IL-6 and IL-8) cytokines from the medium had also been detected by ELISA. The results (Fig. 5d) did not show any significant change between groups. Moreover, ELISA was also used to assess whether MSCs could secrete rat omentin-1; however, we did not detect this in the MSC medium, and the results were further confirmed by wWestern blot and quantitative real-time polymerase chain reaction (qRT-PCR) in MSCs (data not shown), suggesting that MSCs might not be the source of omentin-1.

The data above suggest that omentin-1 could enhance the proangiogenic factor paracrine effect of MSCs via PI3K/Akt, thereby augmenting the endothelial cell capillary tube forming capacity in vitro. 


\section{Discussion}

In the present study, we investigated the effects of omentin- 1 on MSCs and found that omentin- 1 can promote MSC proliferation, inhibit $\mathrm{H}_{2} \mathrm{O}_{2}$-induced apoptosis, enhance angiogenic growth factor secretion, and elevate the ability of MSCs to stimulate tube formation by HUVECs. Moreover, these effects of omentin-1 were shown to be mediated, at least partially, through the PI3K/Akt signaling pathway. To our knowledge, this is the first study to report the beneficial effects of omentin-1 on MSCs and the underlying mechanisms.

Based on promising preclinical and clinical data, MSC therapy has been suggested as a potential therapeutic strategy for tissue repair [38]. Moreover, accumulating evidence suggests that MSCs repair the damaged tissue mainly by secreting cytokines and other paracrine factors to promote angiogenesis, activating endogenous reparative responses $[39,40]$ rather than directly by differentiation and numerical replacement of lost cell mass [40]. However, the success of MSC therapy still has its limitations. One of them is that the small number obtained from the donors requires extensive expansion for therapeutic utility $[7,8]$. The other is that MSC therapy is compromised by the decreased survival of transplanted MSCs mainly due to oxidative stress and hypoxia in the harsh environment $[9,10]$, which in turn inhibits angiogenesis and tissue repair [41-43]. Therefore, to overcome these problems, researchers have attempted to enhance MSC proliferation, survival, and increase the secretion of cytokines for angiogenesis and other tissue repair function.

Omentin-1 is a new fat depot-specific secretory adipokine, the plasma levels of which are significantly decreased in patients with obesity, insulin resistance, diabetes, and cardiovascular diseases such as atherosclerosis, coronary artery disease, and ischemic heart disease $[17,20]$. Although omentin-1 has been reported to exert proproliferation, prosurvival, and proangiogenic functions in various cells via an Akt-dependent mechanism $[22,23,29]$, its specific role and underlying mechanism in MSCs remains unclear.

In the present study, the effects of different concentrations of omentin- $1(100,200,400$, and $800 \mathrm{ng} / \mathrm{ml})$ on MSCs were assessed. All of the concentrations of omentin-1, except $100 \mathrm{ng} / \mathrm{ml}$, had a significant promoting effect on the growth of the MSCs in a time- and concentration-dependent manner. In addition, the number of cells in the S and G2 phases of the cell cycle significantly increased under omentin- 1 exposure and the process was accompanied by upregulation of cyclin D1/E and downregulation of $\mathrm{p} 21 / \mathrm{p} 27$. Of note, the concentration at $100 \mathrm{ng} / \mathrm{ml}$ was significantly lower than the physiological concentration in serum $(200-400 \mathrm{ng} / \mathrm{ml})$ [17, 44], suggesting that physiological and higher concentrations are required for MSC proliferation. Furthermore, we used $\mathrm{H}_{2} \mathrm{O}_{2}$ to induce oxidative stress to MSCs. The results showed that $\mathrm{H}_{2} \mathrm{O}_{2}$ induced higher intracellular ROS and more cellular apoptosis with a mitochondrial membrane potential decrease and caspase- 3 activation. Moreover, excessive ROS could attack the mitochondrial membrane, leading to loss of the potential of the mitochondrial membrane and the consequent apoptosis of MSCs [45]; however, omentin-1 pretreatment could reduce the excessive ROS, restore mitochondrial membrane potential, and inhibit the apoptosis of MSCs in a concentration-dependent manner. In addition, the balance of Bax and Bcl-2 is responsible for the integrity of the mitochondrial membrane and $\Delta \Psi \mathrm{m}$ stabilization [46]. Higher Bax and lower Bcl-2 levels resulted in a loss of $\Delta \Psi \mathrm{m}$ and mitochondrial swelling or disruption [46]. In contrast, our experiment demonstrated that omentin-1 pretreatment upregulated Bcl-2 but downregulated Bax, which contributed to the preservation of mitochondrial function. Caspases are downstream of the $\mathrm{Bcl}-2$ family in the apoptotic cascade and caspase- 3 is one of the key effectors of apoptosis [47]. We further detected the activation of caspase- 3 and found that omentin-1 pretreatment markedly reduced the levels of cleaved caspase- 3 compared with the cells treated with $\mathrm{H}_{2} \mathrm{O}_{2}$ alone. Therefore, these findings suggest that omentin-1 may exert its protective property in oxidative stress-induced MSC apoptosis by reducing the excessive ROS and inhibiting mitochondria-dependent caspase cascades. Furthermore, our data showed that omentin-1 could increase MSC phosphorylated Akt levels in a timeand concentration-dependent manner. However, LY294002, the specific inhibitor of PI3K, not only blocked the activation of Akt induced by omentin-1, but also significantly attenuated the promoting effects of omentin-1 on the growth and survival of MSCs, suggesting that omentin-1 treatment activated Akt and led to MSC proliferation and survival.

Forkhead box O3 (FoxO3a), a transcription factor, is the downstream target of Akt [48]. Moreover, FoxO3a can promote antiproliferation or proapoptosis signaling through either increasing the protein levels of cyclindependent kinase inhibitors [49], or regulating the expression of Bcl-2 family proteins [50]. Activated Akt-mediated phosphorylation and inactivation of FoxO3a improves cell proliferation and survival. Likewise, glycogen synthase kinase-3 $\beta$ (GSK-3 $\beta$ ) also exists downstream of Akt and acts as a key regulator of multiple processes that are critical for the proliferation and apoptosis in various cells, including MSCs [51, 52]. In this present study, we found that FoxO3a and GSK-3 $\beta$ were phosphorylated by omentin-1, which might be a direct result of Akt activation, and this was reversed in the presence of LY294002. This suggested a potential role of FoxO3a and GSK-3 $\beta$ in omentin-1-induced MSC proliferation and survival. 
In addition, omentin- 1 has also been observed to exhibit antiproliferative and proapoptotic effects via the PI3K/Akt pathway in other types of cells, such as human osteoblasts [27], mouse neural stem cells [53], cardiomyocytes [23], and endothelial cells [22]. In contrast, Zhang and colleagues [54] provided evidence that omentin-1, as an anticancer factor, inhibited human hepatocellular carcinoma cell proliferation and survival via the JNK signaling pathway. It was also found that omentin-1 attenuated neointimal formation after arterial injury and suppressed vascular smooth muscle cell proliferation through AMPK-ERK-dependent mechanisms [55]. One possible explanation for this discrepancy could be that the activity of these signaling pathways is differentially controlled in specific cells in response to omentin-1 treatment, and the specificity of the regulation is dependent on cell type and/or its exposure environment.

During the past decade, it has been demonstrated that MSCs can promote angiogenesis by the secretion of proangiogenic factors (e.g., VEGF, IGF-1, HGF, and FGF2) that contribute to tissue repair and enhance the reparative process $[41,56,57]$. Thus, various strategies have been adopted to upregulate the secretion of angiogenic factors in MSCs, such as gene transfer [41] and culture under hypoxic conditions [58]. Although it has also been reported that omentin-1 could directly promote endothelial cell function and revascularization in the hind limb ischemia mouse model [22], the indirect effect of omentin-1 on angiogenesis through MSCs remains unclear. In this study, we observed that conditioned medium from omentin-1-pretreated MSCs significantly increased the tube length relative to the conditioned medium from untreated MSCs and basal medium. Furthermore, we confirmed that proangiogenic factors (VEGF, FGF-2, HGF, and IGF-1) from omentin1-pretreated MSC conditioned medium had a higher level than that from untreated MSCs; thus we concluded that omentin-1 could augment endothelial cell capillary tube forming capacity in vitro at least partially due to the upregulation of the secretion of angiogenic factors by MSCs. Additionally, a blockade of the Akt pathway caused a reduction in the tube-forming capacity and angiogenic cytokines of conditioned medium from MSCs pretreated with omentin-1. Together, these data revealed that the proangiogenic effects of omentin-1 on MSCs are mediated at least partially through the PI3K/Akt signaling pathway. However, these results do not rule out the proangiogenic effects of other factors that are secreted by MSCs, such as Ang-1, Ang-2, IL-6, and PLGF. It will be interesting to acquire more information on the angiogenic factors found in the MSC secretome induced by omentin-1. In addition to proangiogenic factors, we also detected several main anti-inflammatory (IL-1ra and TSG-6) and proinflammatory (IL-6 and IL-8) cytokines from the MSC medium; however, there was no significant change between groups, suggesting that omentin-1 might at least have no effects on the secretion of the inflammation-associated cytokines mentioned above by MSCs.

Of note, the signaling pathways mediating the protective effects of omentin-1 are complex and never exclusive. Several studies have argued that AMPK could be activated by omentin-1 and involved in the regulation of proliferation and apoptosis [22, 23, 59]; whether this pathway also contributes to the beneficial influence of omentin-1 and its possible crosstalk with Akt require further research. Moreover, contributions of other adipokines, especially those that exert positive effects on health such as C1q/TNF-related protein 9 (CTRP9), must be elucidated in future studies.

\section{Conclusion}

Overall, the results of the present study provide preliminary evidence indicating that omentin-1 has beneficial effects on MSCs by promoting proliferation, inhibiting apoptosis, increasing secretion of angiogenic cytokines, and enhancing the ability for stimulating tube formation by HUVECs. In addition, the beneficial effects of omentin-1 are possibly a result of the activation of the PI3K/Akt signaling pathway. These data collectively demonstrate that omentin-1 may be considered a candidate for optimizing MSC-based cell therapy.

\section{Abbreviations}

AMPK: AMP-activated protein kinase; CCK-8: Cell counting kit-8; CTRP9: C1q/ TNF-related protein 9; DCFH-DA: 2',7'-Dichlorodihydrofluorescein diacetate; DMEM/F12: Dulbecco's modified Eagle's medium/nutrient mixture F-12; EdU: 5-Ethynyl-2'-deoxyuridine; ELISA: Enzyme-linked immunosorbent assay; FGF-2: Fibroblast growth factor-2; FoxO3a: Forkhead box O3; GSK-33: Glycogen synthase kinase-3 $\beta$; HGF: Hepatocyte growth factor; HUVEC: Human umbilical vein endothelial cell; IGF-1: Insulin-like growth factor-1; IL: Interleukin; IL1ra: Interleukin-1 receptor antagonist; MSC: Mesenchymal stem cell; pAkt: Phosphorylated Akt; PBS: Phosphate-buffered solution; PI: Propidium iodide; PVDF: Polyvinylidene difluoride; ROS: Reactive oxygen species; SD: SpragueDawley; SDS-PAGE: Sodium dodecyl sulfate-polyacrylamide gel electrophoresis; TBS: Tris-buffered saline; TBS-T: TBS with Tween-20; TSG-6: Tumor necrosis factor-stimulated gene-6; VEGF: Vascular endothelial growth factor; $\Delta \psi \mathrm{m}$ or MMP: Mitochondrial membrane potential

\section{Acknowledgements \\ The authors thank Dr. Wei Liu for her expert assistance with experimental design and excellent technical assistance, and Dr. Meng Sun for her help with statistical analysis. Drs. Wei Liu and Meng Sun are members of the Key Laboratory of Myocardial Ischemia Mechanism and Treatment (Harbin Medical University), Ministry of Education.}

\section{Funding}

This study was supported by grants from the Key Program of the National Natural Science Foundation of China (Grant No. 81330033).

\section{Availability of data and materials}

The datasets used and/or analyzed during the current study are available from the corresponding author on reasonable request. 


\section{Authors' contributions}

LY contributed to the experimental design, carried out the molecular biology experiments, performed the statistical analysis, and drafted the manuscript. DH participated in the design of the study and revised the manuscript. XL was responsible for MSC culture, statistical analysis, and helped to draft the manuscript. YW carried out the flow cytometry assay and revised the manuscript. JL participated in the EdU and Hoechst 33342 dye assays and helped to draft the manuscript. FL participated in the design of the study, performed the statistical analysis, and helped to revise the manuscript. BY conceived of the study, and participated in its design and coordination, and helped to draft the manuscript. All authors read and approved the final manuscript.

\section{Ethics approval}

All of the study procedures were approved by the Institutional Animal Care and Use Committee of Harbin Medical University (Reference No. KY2016-180). This study was conducted in compliance with the Guide for the Care and Use of Laboratory Animals published by the National Academy Press (National Institutes of Health, revised in 1996).

\section{Consent for publication}

Not applicable.

\section{Competing interests}

The authors declare that they have no competing interests.

\section{Publisher's Note}

Springer Nature remains neutral with regard to jurisdictional claims in published maps and institutional affiliations.

Received: 13 December 2016 Revised: 1 July 2017

Accepted: 18 September 2017 Published online: 10 October 2017

\section{References}

1. Wollert KC, Meyer GP, Lotz J, Ringes-Lichtenberg S, Lippolt P, Breidenbach C, Fichtner S, Korte T, Hornig B, Messinger D, Arseniev L, Hertenstein B, Ganser A, Drexler H. Intracoronary autologous bone-marrow cell transfer after myocardial infarction: the BOOST randomised controlled clinical trial. Lancet. 2004;364:141-8. doi:10.1016/S0140-6736(04)16626-9.

2. Honmou O, Onodera R, Sasaki M, Waxman SG, Kocsis JD. Mesenchymal stem cells: therapeutic outlook for stroke. Trends Mol Med. 2012;18:292-7.

3. Madonna R, Taylor DA, Geng YJ, De Caterina R, Shelat H, Perin EC, Willerson JT. Transplantation of mesenchymal cells rejuvenated by the overexpression of telomerase and myocardin promotes revascularization and tissue repair in a murine model of hindlimb ischemia. Circ Res. 2013;113:902-14. doi:10. 1161/CIRCRESAHA.113.301690.

4. Pittenger MF, Mackay AM, Beck SC, Jaiswal RK, Douglas R, Mosca JD, Moorman MA, Simonetti DW, Craig S, Marshak DR. Multilineage potential of adult human mesenchymal stem cells. Science. 1999;284:143-7.

5. Dow J, Simkhovich BZ, Kedes L, Kloner RA. Washout of transplanted cells from the heart: a potential new hurdle for cell transplantation therapy. Cardiovasc Res. 2005;67:301-7. doi:10.1016/j.cardiores.2005.04.011.

6. Wei H, Li Z, Hu S, Chen X, Cong X. Apoptosis of mesenchymal stem cells induced by hydrogen peroxide concerns both endoplasmic reticulum stress and mitochondrial death pathway through regulation of caspases, p38 and JNK. J Cell Biochem. 2010;111:967-78. doi:10.1002/jcb.22785.

7. Tamama K, Fan VH, Griffith LG, Blair HC, Wells A. Epidermal growth factor as a candidate for ex vivo expansion of bone marrow-derived mesenchymal stem cells. Stem Cells. 2006;24:686-95. doi:10.1634/stemcells.2005-0176.

8. Choi SC, Kim SJ, Choi JH, Park CY, Shim WJ, Lim DS. Fibroblast growth factor- 2 and -4 promote the proliferation of bone marrow mesenchymal stem cells by the activation of the PI3K-Akt and ERK1/2 signaling pathways. Stem Cells Dev. 2008;17:725-36. doi:10.1089/scd.2007.0230.

9. Mangi AA, Noiseux N, Kong D, He H, Rezvani M, Ingwall JS, Dzau VJ. Mesenchymal stem cells modified with Akt prevent remodeling and restore performance of infarcted hearts. Nat Med. 2003;9:1195-201. doi:10.1038/nm912.

10. Lim SY, Kim YS, Ahn Y, Jeong MH, Hong MH, Joo SY, Nam Kl, Cho JG, Kang PM, Park JC. The effects of mesenchymal stem cells transduced with Akt in a porcine myocardial infarction model. Cardiovasc Res. 2006;70:530-42. doi: 10.1016/j.cardiores.2006.02.016.
11. Piao W, Wang H, Inoue M, Hasegawa M, Hamada H, Huang J. Transplantation of Sendai viral angiopoietin-1-modified mesenchymal stem cells for ischemic limb disease. Angiogenesis. 2010;13:203-10. doi:10.1007/ s10456-010-9169-x.

12. Gnecchi M, He H, Noiseux N, Liang OD, Zhang L, Morello F, Mu H, Melo LG, Pratt RE, Ingwall JS, Dzau VJ. Evidence supporting paracrine hypothesis for Akt-modified mesenchymal stem cell-mediated cardiac protection and functional improvement. FASEB J. 2006;20:661-9. doi:10.1096/fj.05-5211 com.

13. Shibata R, Ohashi K, Murohara T, Ouchi N. The potential of adipokines as therapeutic agents for cardiovascular disease. Cytokine Growth Factor Rev. 2014;25:483-7. doi:10.1016/j.cytogfr.2014.07.005.

14. Jialal I, Devaraj S, Kaur H, Adams-Huet B, Bremer AA. Increased chemerin and decreased omentin-1 in both adipose tissue and plasma in nascent metabolic syndrome. J Clin Endocrinol Metab. 2013;98:E514-7. doi:10.1210/jc.2012-3673.

15. Koleva DI, Orbetzova MM, Atanassova PK. Adipose tissue hormones and appetite and body weight regulators in insulin resistance. Folia Med (Plovdiv). 2013;55:25-32

16. Yang RZ, Lee MJ, Hu H, Pray J, Wu HB, Hansen BC, Shuldiner AR, Fried SK, McLenithan JC, Gong DW. Identification of omentin as a novel depotspecific adipokine in human adipose tissue: possible role in modulating insulin action. Am J Physiol Endocrinol Metab. 2006;290:E1253-61. doi:10. 1152/ajpendo.00572.2004.

17. de Souza Batista CM, Yang RZ, Lee MJ, Glynn NM, Yu DZ, Pray J, Ndubuizu K, Patil S, Schwartz A, Kligman M, Fried SK, Gong DW, Shuldiner AR, Pollin TI, McLenithan JC. Omentin plasma levels and gene expression are decreased in obesity. Diabetes. 2007;56:1655-61. doi:10.2337/db06-1506.

18. Herder C, Carstensen M, Ouwens DM. Anti-inflammatory cytokines and risk of type 2 diabetes. Diabetes Obes Metab. 2013;15 Suppl 3:39-50. doi:10. 1111/dom.12155.

19. Yan P, Li L, Yang M, Liu D, Liu H, Boden G, Yang G. Effects of the longacting human glucagon-like peptide-1 analog liraglutide on plasma omentin-1 levels in patients with type 2 diabetes mellitus. Diabetes Res Clin Pract. 2011;92:368-74. doi:10.1016/j.diabres.2011.02.030

20. Zhong X, Zhang HY, Tan H, Zhou Y, Liu FL, Chen FQ, Shang DY. Association of serum omentin-1 levels with coronary artery disease. Acta Pharmacol Sin. 2011;32:873-8. doi:10.1038/aps.2011.26.

21. Panagiotou G, Mu L, Na B, Mukamal KJ, Mantzoros CS. Circulating irisin, omentin-1, and lipoprotein subparticles in adults at higher cardiovascular risk. Metabolism. 2014;63:1265-71. doi:10.1016/j.metabol.2014.06.001.

22. Maruyama S, Shibata R, Kikuchi R, Izumiya Y, Rokutanda T, Araki S, Kataoka Y, Ohashi K, Daida H, Kihara S, Ogawa H, Murohara T, Ouchi N. Fat-derived factor omentin stimulates endothelial cell function and ischemia-induced revascularization via endothelial nitric oxide synthase-dependent mechanism. J Biol Chem. 2012;287:408-17. doi:10.1074/jbc.M111.261818.

23. Kataoka Y, Shibata R, Ohashi K, Kambara T, Enomoto T, Uemura Y, et al. Omentin prevents myocardial ischemic injury through AMP-activated protein kinase- and Akt-dependent mechanisms. J Am Coll Cardiol. 2014;63: 2722-33. doi:10.1016/j.jacc.2014.03.032.

24. Zhang Q, Yang YJ, Wang H, Dong QT, Wang TJ, Qian HY, Xu H. Autophagy activation: a novel mechanism of atorvastatin to protect mesenchymal stem cells from hypoxia and serum deprivation via AMP-activated protein kinase/ mammalian target of rapamycin pathway. Stem Cells Dev. 2012;21:1321-32. doi:10.1089/scd.2011.0684.

25. Zhang F, Cui J, Liu X, Lv B, Liu X, Xie Z, Yu B. Roles of microRNA-34a targeting SIRT1 in mesenchymal stem cells. Stem Cell Res Ther. 2015;6:195. doi:10.1186/s13287-015-0187-x.

26. Hiramatsu-Ito M, Shibata R, Ohashi K, Uemura Y, Kanemura N, Kambara T, et al. Omentin attenuates atherosclerotic lesion formation in apolipoprotein Edeficient mice. Cardiovasc Res. 2016;110:107-17. doi:10.1093/cvr/crv282.

27. Wu SS, Liang QH, Liu Y, Cui RR, Yuan LQ, Liao EY. Omentin-1 stimulates human osteoblast proliferation through PI3K/Akt signal pathway. Int J Endocrinol. 2013. doi:10.1155/2013/368970.

28. Duan XY, Xie PL, Ma YL, Tang SY. Omentin inhibits osteoblastic differentiation of calcifying vascular smooth muscle cells through the PI3K Akt pathway. Amino Acids. 2011;41:1223-31. doi:10.1007/s00726-010-0800-3.

29. Qi D, Tang X, He J, Wang D, Zhao Y, Deng W, Deng X, Zhou G, Xia J, Zhong X, Pu S. Omentin protects against LPS-induced ARDS through suppressing pulmonary inflammation and promoting endothelial barrier via an Akt/eNOSdependent mechanism. Cell Death Dis. 2016;7:e2360. doi:10.1038/cddis.2016.265.

30. Johnson AM, Kartha CC. Proliferation of murine c-kit(pos) cardiac stem cells stimulated with IGF-1 is associated with Akt-1 mediated phosphorylation and 
nuclear export of FoxO3a and its effect on downstream cell cycle regulators. Growth Factors. 2014;32:53-62. doi:10.3109/08977194.2014.889694.

31. Chuang DM, Wang Z, Chiu CT. GSK-3 as a target for lithium-induced neuroprotection against excitotoxicity in neuronal cultures and animal models of ischemic stroke. Front Mol Neurosci. 2011;:15. doi:10.3389/fnmol.2011.00015.

32. Zhang Z, Li S, Cui M, Gao X, Sun D, Qin X, Narsinh K, Li C, Jia H, Li C, Han Y, Wang $\mathrm{H}$, Cao F. Rosuvastatin enhances the therapeutic efficacy of adipose-derived mesenchymal stem cells for myocardial infarction via PI3K/Akt and MEKJERK pathways. Basic Res Cardiol. 2013;108:333. doi:10.1007/500395-013-0333-5.

33. Son TW, Yun SP, Yong MS, Seo BN, Ryu JM, Youn HY, Oh YM, Han HJ. Netrin-1 protects hypoxia-induced mitochondrial apoptosis through HSP27 expression via DCC- and integrin a6ß4-dependent Akt, GSK-3ß, and HSF-1 in mesenchymal stem cells. Cell Death Dis. 2013;4:e563.

34. Zhu Z, Yin J, Guan J, Hu B, Niu X, Jin D, Wang Y, Zhang C. Lithium stimulates human bone marrow derived mesenchymal stem cell proliferation through GSK-3 $\beta$-dependent $\beta$-catenin/Wnt pathway activation. FEBS J. 2014;281:5371-89.

35. Shen H, Zhou E, Wei X, Fu Z, Niu C, Li Y, Pan B, Mathew AV, Wang X, Pennathur S, Zheng L, Wang Y. High density lipoprotein promotes proliferation of adipose-derived stem cells via S1P1 receptor and Akt, ERK1/2 signal pathways. Stem Cell Res Ther. 2015;6:95. doi:10.1186/s13287-015-0090-5.

36. Wang XY, Fan XS, Cai L, Liu S, Cong XF, Chen X. Lysophosphatidic acid rescues bone mesenchymal stem cells from hydrogen peroxide-induced apoptosis. Apoptosis. 2015;20:273-84. doi:10.1007/s10495-014-1074-0.

37. Giannoni E, Buricchi F, Grimaldi G, Parri M, Cialdai F, Taddei ML, Raugei G, Ramponi G, Chiarugi P. Redox regulation of anoikis: reactive oxygen species as essential mediators of cell survival. Cell Death Differ. 2008;15:867-78. doi:10.1038/cdd.2008.3.

38. Gao LR, Chen Y, Zhang NK, Yang XL, Liu HL, Wang ZG, et al. Intracoronary infusion of Wharton's jelly-derived mesenchymal stem cells in acute myocardial infarction: double-blind, randomized controlled trial. BMC Med. 2015;13:162. doi:10.1186/s12916-015-0399-z.

39. Gnecchi M, Zhang Z, Ni A, Dzau VJ. Paracrine mechanisms in adult stem cell signaling and therapy. Circ Res. 2008;103:1204-19. doi:10.1161/CIRCRESAHA. 108.176826 .

40. Parekkadan B, Milwid JM. Mesenchymal stem cells as therapeutics. Annu Rev Biomed Eng. 2010;12:87-117.

41. Deuse T, Peter C, Fedak PW, Doyle T, Reichenspurner H, Zimmermann WH, Eschenhagen T, Stein W, Wu JC, Robbins RC, Schrepfer S. Hepatocyte growth factor or vascular endothelial growth factor gene transfer maximizes mesenchymal stem cell-based myocardial salvage after acute myocardial infarction. Circulation. 2009;120:S247-54.

42. Kinnaird T, Stabile E, Burnett MS, Shou M, Lee CW, Barr S, Fuchs S, Epstein SE. Local delivery of marrow-derived stromal cells augments collateral perfusion through paracrine mechanisms. Circulation. 2004;109:1543-9.

43. Kinnaird T, Stabile E, Burnett MS, Lee CW, Barr S, Fuchs S, Epstein SE. Marrow-derived stromal cells express genes encoding a broad spectrum of arteriogenic cytokines and promote in vitro and in vivo arteriogenesis through paracrine mechanisms. Circ Res. 2004;94:678-85.

44. Tan YL, Zheng XL, Tang CK. The protective functions of omentin in cardiovascular diseases. Clin Chim Acta. 2015;448:98-106. doi:10.1016/j.cca.2015.05.019.

45. Zhou L, Chen X, Liu T, Gong Y, Chen S, Pan G, Cui W, Luo ZP, Pei M, Yang $\mathrm{H}$, He F. Melatonin reverses $\mathrm{H}_{2} \mathrm{O} 2$-induced premature senescence in mesenchymal stem cells via the SIRT1-dependent pathway. J Pineal Res. 2015:59:190-205. doi:10.1111/jpi.12250.

46. Desagher S, Martinou JC. Mitochondria as the central control point of apoptosis. Trends Cell Biol. 2000;10:369-77.

47. Kiraz Y, Adan A, Kartal YM, Baran Y. Major apoptotic mechanisms and genes involved in apoptosis. Tumour Biol. 2016;37:8471-86. doi:10.1007/s13277016-5035-9

48. Zhang $X$, Tang N, Hadden TJ, Rishi AK. Akt, FoxO and regulation of apoptosis. Biochim Biophys Acta. 2011;1813(11):1978-86. doi:10.1016/j.bbamcr.2011.03.010.

49. Seoane J, Le HV, Shen L, Anderson SA, Massagué J. Integration of Smad and forkhead pathways in the control of neuroepithelial and glioblastoma cell proliferation. Cell. 2004;117:211-23.

50. LV Y, Song S, Zhang K, Gao H, Ma R. CHIP regulates AKT/FoxO/Bim signaling in MCF7 and MCF10A cells. PLoS One. 2013;8:e83312. doi:10.1371/journal. pone.0083312

51. Zhang B, Liu N, Shi H, Wu H, Gao Y, He H, Gu B, Liu H. High glucose microenvironments inhibit the proliferation and migration of bone mesenchymal stem cells by activating GSK3 $\beta$. J Bone Miner Metab. 2016;34:140-50.
52. Kim SY, Son WS, Park MC, Kim CM, Cha BH, Yoon KJ, Lee SH, Park SG. ARSinteracting multi-functional protein 1 induces proliferation of human bone marrow-derived mesenchymal stem cells by accumulation of $\beta$-catenin via fibroblast growth factor receptor 2-mediated activation of Akt. Stem Cells Dev. 2013;22:2630-40.

53. Zhao LR, Du YJ, Chen L, Liu ZG, Jia XY, Pan YH, Liu JF, Liu B. Omentin-1 promotes the growth of neural stem cells via activation of Akt signaling. Mol Med Rep. 2015;11(3):1859-64. doi:10.3892/mmr.2014.2937.

54. Zhang YY, Zhou LM. Omentin-1, a new adipokine, promotes apoptosis through regulating Sirt1-dependent p53 deacetylation in hepatocellular carcinoma cells. Eur J Pharmacol. 2013;698:137-44. doi:10.1016/.ejphar.2012.11.016.

55. Uemura Y, Shibata R, Kanemura N, Ohashi K, Kambara T, Hiramatsu-tto M, Enomoto T, Yuasa D, Joki Y, Matsuo K, Ito M, Hayakawa S, Ogawa H, Murohara T, Ouchi N. Adipose-derived protein omentin prevents neointimal formation after arterial injury. FASEB J. 2015:29:141-51. doi:10.1096/fj.14-258129.

56. Golpanian S, Wolf A, Hatzistergos KE, Hare JM. Rebuilding the damaged heart: mesenchymal stem cells, cell-based therapy, and engineered heart tissue. Physiol Rev. 2016;96:1127-68. doi:10.1152/physrev.00019.2015.

57. Bronckaers A, Hilkens P, Martens W, Gervois P, Ratajczak J, Struys T, Lambrichts I. Mesenchymal stem/stromal cells as a pharmacological and therapeutic approach to accelerate angiogenesis. Pharmacol Ther. 2014;143: 181-96. doi:10.1016/j.pharmthera.2014.02.013.

58. Rosova I, Dao M, Capoccia B, Link D, Nolta JA. Hypoxic preconditioning results in increased motility and improved therapeutic potential of human mesenchymal stem cells. Stem Cells. 2008;26:2173-82. doi:10.1634/stemcells. 2007-1104.

59. Matsuo K, Shibata R, Ohashi K, Kambara T, Uemura Y, Hiramatsu-lto M, Enomoto T, Yuasa D, Joki Y, Ito M, Hayakawa S, Ogawa H, Kihara S, Murohara T, Ouchi N. Omentin functions to attenuate cardiac hypertrophic response. J Mol Cell Cardiol. 2015;79:195-202. doi:10.1016/j.yjmcc.2014.11.019.

\section{Submit your next manuscript to BioMed Central and we will help you at every step:}

- We accept pre-submission inquiries

- Our selector tool helps you to find the most relevant journal

- We provide round the clock customer support

- Convenient online submission

- Thorough peer review

- Inclusion in PubMed and all major indexing services

- Maximum visibility for your research

Submit your manuscript at www.biomedcentral.com/submit
) Biomed Central 